\title{
Uso del espacio semiárido por poblaciones prehispánicas: el papel de los paisajes de dunas como eco-refugios en el Centro de Argentina
}

\author{
Guillermo Heider, Esteban G. Jobbágy, Alfonsina Tripaldi
}

\section{Guillermo Heider}

guillermoheider@hotmail.com

CONICET-CGT San Luis. Dpto. de Geología, Facultad Cs. Físico Matemáticas y Naturales. Universidad Nacional de San Luis. Ejército de Los Andes 950, San Luis (5700), Argentina.

\section{Esteban G. Jobbágy}

jobbagy@unsl.edu.ar

Grupo de Estudios Ambientales - IMASL, CONICET, San Luis, Argentina. Ejército de Los Andes 950, San Luis (5700), Argentina.

\section{Alfonsina Tripaldi}

alfo@gl.fcen.uba.ar

IGEBA-UBA-CONICET, Departamento de Ciencias Geológicas, Universidad de Buenos Aires, Ciudad Universitaria, Buenos Aires, C1428EHA, Argentina.

BOL. SOC. GEOL. MEX. 2019

VOL. 71 NO. 2

P. $229-248$

http://dx.doi.org/10.18268/BSGM2019v7 ln2al

\section{RESUMEN}

Las sociedades humanas que habitaron las zonas áridas y semiáridas de todo el planeta han tenido en el pasado, igual que en la actualidad, al agua como un recurso crítico en su toma de decisiones. Desde las ciencias humanas y naturales se han hecho aportes para comprender los patrones de uso del espacio de estos grupos y el manejo (en un sentido amplísimo del término, desde lo estrictamente económico a lo simbólico) que tuvieron del recurso hídrico. En este trabajo buscamos entender el uso del espacio y la movilidad de los grupos humanos que habitaron un sector de la Diagonal Árida Sudamericana ubicado en el centro de Argentina, desde la interface de las ciencias geológicas, hidrológicas y ecológicas. El área de estudio fue conocida como "Las Travesías" desde el tiempo de contacto hispano-indígena debido a las dificultades que imponían para atravesarla, la carencia de agua y el bajo poblamiento. Esta noción europea del paisaje resulta inapropiada a la luz de las evidencias arqueológicas de pueblos originarios en el territorio desde hace $c a .8000$ años $\mathrm{AP}$, que indicarían la presencia de recursos hídricos previamente subestimados. Combinando el análisis geomorfológico e hidrológico de los paisajes de dunas prevalentes en gran parte de Las Travesías con las evidencias arqueológicas y etnográficas existentes, proponemo un modelo de ocupación del espacio de la región con mayor déficit hídrico de Sudamérica, en el que esto paisajes funcionaron como eco-refugios. Estos sistemas de dunas suelen albergar aguas subterráneas de bajo contenido de sales y poca profundidad, gracias al alto drenaje del sustrato arenoso que permite que una fracción apreciable de las lluvias, aun en climas áridos, escape de la evapotranspiración y recargue el acuífero freático. Evidencia actual y etnográfica sugiere que la ocupación y disturbio persistente de estos sistemas de dunas aumenta su capacidad de provee agua al deteriorar la cubierta vegetal y así (i) restringir la evapotranspiración y aumentar la recarga y (ii) deprimir zonas del terreno por erosión, acortando la profundidad al manto freático. Un conjunto relativamente limitado pero eficiente de estrategias para la cosecha de agua, sumado a una movilidad estacional y el conocimiento profundo del espacio, se plantean como estrategias que permitieron no solo la exploración y colonización inicial de Las Travesías sino, posteriormente también, su ocupación definitiva.

Palabras clave: Ocupación humana prehispánica; Diagonal Árida Sudamericana; Paisajes de dunas; Eco-refugios; Geomorfología; Acuíferos.

\section{ABSTRACT}

Both in the past as in the present, the native peoples who inhabited the arid and semi-arid zones of the entire planet have had water as a critical resource in their decision-making. From the human and natural sciences, contributions have been made to understand the patterns of the use of space of these groups and the management (in a very broad sense of the term, from the strictly economic to the symbolic one) of the water resource. The aim of this work is to understand the use of space and mobility of the human groups that inhabited a sector of the Arid South American Diagonal, located in the center of Argentina, from the interface of the geological, hydrological, and ecological sciences. The study area was known as "Las Travesias" from the time of the Hispanic-Indigenous contact due to the difficulties of crossing it, because of the lack of water and the low population. This European notion of the landscape is inappropriate in the light of the archaeological evidence of indigenous peoples in the territory since ca. 8000 years BP. These occupations suggest the presence of previously underestimated water resources. Combining the geomorphological and hydrological analyses of the dune landscapes, prevalent in a large part of Las Travesias, with the existing archaeological and ethnographic evidences, we propose a model of space occupation with greatest water deficit in South America and, in which, these landscapes have functioned as eco-shelters. These systems of dunes tend to hold groundwater with low salt content and shallowness due to the high drainage of the sandy substrate that allows a considerable fraction of the rains, even in arid climates, escape evapotranspiration and recharge the phreatic aquifer. Modern and ethnographic evidence suggests that the persistent occupation and disturbance of these dune systems increases their ability to provide water by damaging the vegetation cover, restricting evapotranspiration, increasing recharge, and depressing areas of the land by erosion, shortening the depth to the water table. A relatively small but efficient set of strategies for harvesting water, together with seasonal mobility and a deep knowledge of the space, are proposed as the strategies that allowed not only the exploration and initial colonization of Las Travesias but also the definitive occupation of this space.

Keywords: Prehispanic human Occupation; South American Arid Diagonal; dune landscapes; Eco-shelter; Geomorphology; Aquifer. 


\section{Introducción}

Existen diversos sectores del centro-oeste de Argentina que se caracterizan por su clima árido y una escasa oferta de agua y que han sido considerados desde el siglo XVI como barreras geográficas, capaces de aislar regiones enteras (Pastor y Boixados, 2016). Estos sectores, que ocupan $200000 \mathrm{~km}^{2} \mathrm{de}$ llanuras y sierras bajas $\left(-30^{\circ}\right.$ a $-38^{\circ}$ de latitud, $-65^{\circ}$ a $-68^{\circ}$ de longitud), fueron denominados "Las Travesías", a partir de las experiencias de los primeros españoles que intentaron atravesarlas para unir los oasis cordilleranos de Mendoza y San Juan con los asentamientos serranos de San Luis o Córdoba, e incluso con Buenos Aires. Son cuatro los sectores que recibieron esta denominación, los cuales incluyen: (a) la porción sur de la provincia de San Luis, (b) el centro-este y noreste de la provincia de Mendoza, al sudeste de la provincia de San Juan y el centro-oeste de San Luis, (c) los Llanos de la Rioja y (d) el oeste de la provincia de La Pampa (Figura 1). Como resultado de las limitaciones de los españoles para recorrer y poblar estos territorios, se registró una relativa continuidad de las trayectorias históricas locales de los pueblos originarios con posterioridad al contacto hispano-indígena y, por otra parte, una menor cantidad de fuentes históricas plausibles de ser utilizadas para el análisis etnohistórico (de la Cruz, 1835; Canals Frau, 1945, 1950; Parisii, 1991-1992, 1995; Pastor y Boixados, 2016, entre otros). ¿Cómo lograron estos pueblos resolver las limitaciones hídricas? ¿Qué recursos y estrategias les permitieron habitar Las Travesías? Este trabajo aborda estos interrogantes a partir de la confluencia de información geomorfológica, hidrológica, ecológica, arqueológica y etnográfica.

Durante las últimas décadas de siglo XX tuvo lugar una importante modificación teórica en

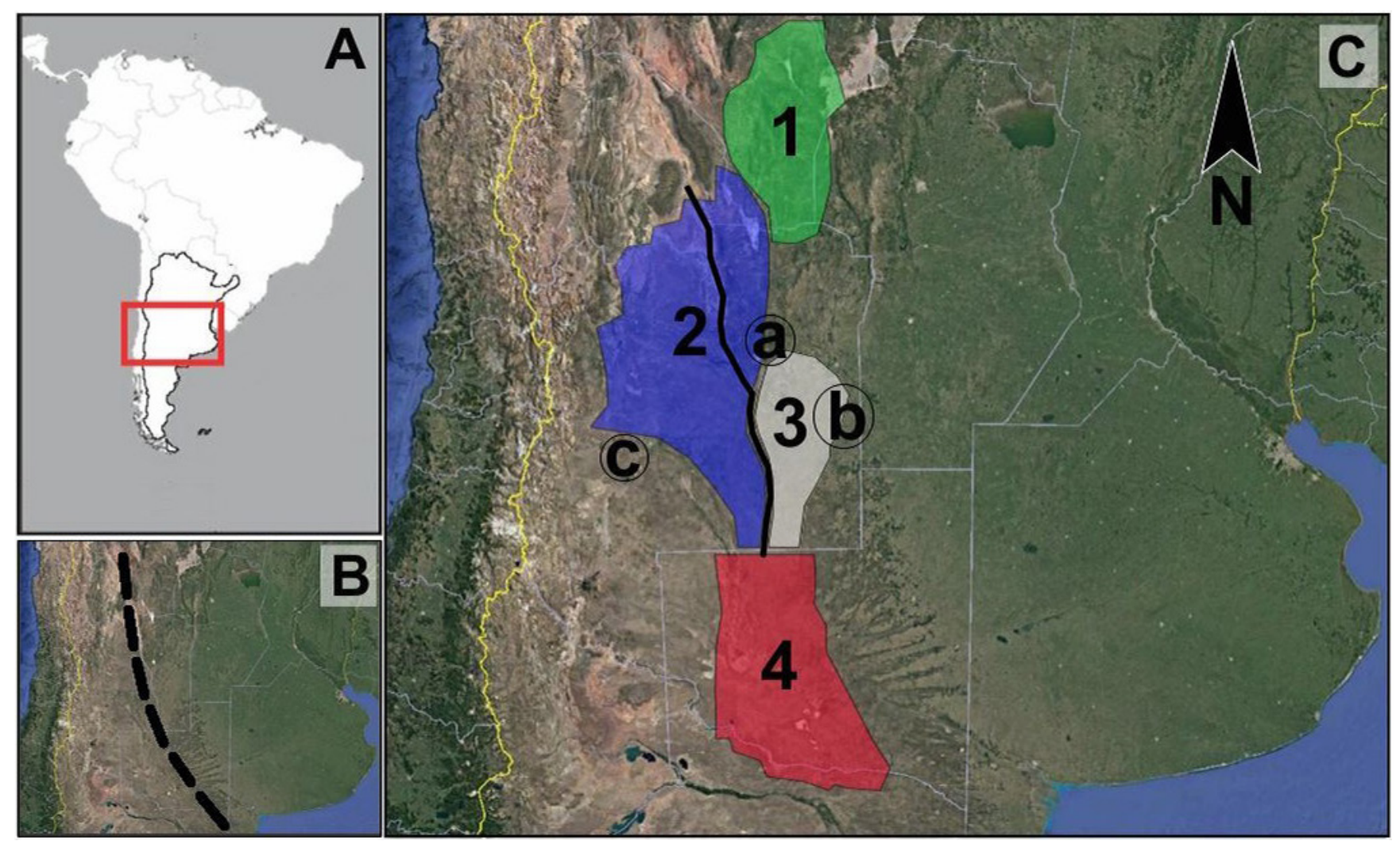

Figura 1 Las Travesías de la Diagonal Árida Sudamericana. A-B: Ubicación de la Diagonal Árida Sudamericana en el Centro de Argentina (demarcada con línea punteada negra). C: Detalle de Las Travesías: (1) Llanos de La Rioja, (2) Travesía Grande, (3) Travesía Puntana, (4) Travesía del Oeste Pampeana; Ubicación de (a) Laguna de Bebedero; (b) Lagunas Los Pocitos y Primera Laguna; (c) Gruta del Indio; Río Desaguadero-Salado (línea continua negra). 
cuanto a la relación grupos humanos/entorno ambiental, asumiéndose en buena parte de la comunidad científica que los contextos ecológicos en los que los grupos sociales toman sus decisiones deben ser tenidos en cuenta para la construcción de modelos de ocupación y uso del espacio. En este sentido, las estrategias sociales plausibles de utilización por parte de los grupos locales se verían restringidas a un stock limitado de respuestas ligadas a las características del ambiente (Butzer, 1989; Jones et al., 1999; Dincauze, 2000; Dearing, 2006; Leroy, 2006; Morales et al., 2009, entre muchos otros). La designación de Travesías como sinónimo de desiertos, recayó sobre algunas áreas extensas de Argentina y tuvo una clara connotación negativa al momento de interpretar la interacción entre los grupos humanos y el territorio. En gran medida estos sectores fueron relegados en las agendas de las investigaciones arqueológicas, prefiriéndose espacios en los que las condiciones climáticas pretéritas se juzgaban como más propicias para la ocupación humana (véase Chiavazza, 2007, 2015; Berón, 2013; Ots et al., 2015; Heider y Curtoni, 2016, entre otros). Sin embargo, el registro material demuestra la presencia humana en Las Travesías de la Diagonal Árida Sudamericana (DAS) desde, al menos, ca. 8000 años AP (Berón, 2016; Rivero y Heider, 2017, entre otros). Puede observarse, en términos de modelos biogeográficos de poblamiento regional, que cada sector dentro de Las Travesías tuvo trayectorias particulares en cuanto a la exploración, colonización y ocupación efectiva del espacio (Borrero, 19891990). Aun así, es posible identificar una serie de recurrencias surgidas del análisis de sus registros arqueológicos y etnográficos. Entre ellas pueden enumerarse las primeras evidencias de ocupación hacia finales del Holoceno temprano, los circuitos de movilidad fuertemente ligados a la disponibilidad de agua, la baja incidencia de los recursos domesticados en la subsistencia, la incorporación de nuevas tecnologías (i.e. cerámica, arco y flecha) hacia finales del Holoceno, ca. 2000 AP, la interacción social a larga distancia, la sacralización de sectores del espacio con fuerte vinculación al recurso hídrico, un aumento demográfico en los últimos ca. 1500 años AP, con una reducción de la movilidad y la reocupación de algunos espacios para el mismo momento (Chiavazza, 2012; Pastor, 2014; Heider, 2015; Ots et al., 2015; Berón, 2016; García, 2017, entre otros).

Entre los puntos mencionados, la reocupación del espacio en Las Travesías es el que nos interesa abordar aquí. Para ello, tomamos como caso de estudio el centro-sur de la provincia de San Luis y el área vecina del noreste de Mendoza, caracterizados por un paisaje de dunas dentro de las cuales se identifica la mayor cantidad de sitios arqueológicos (Figura 2). Otros sectores donde se recupera material arqueológico, en menor medida, son lomas elevadas aledañas a cauces secos de ríos y las porciones medias/bajas de cuencas endorreicas. Las preguntas específicas que surgen son: ¿La distribución espacial de los sitios responde a un sesgo de investigación? ¿Por qué los grupos humanos se establecían en sectores donde no siempre se contaba con agua en superficie? ¿Las áreas que presentan actualmente condiciones semiáridas las tuvieron también durante todo el Holoceno? ¿Qué características del paisaje las hacían atractivas? ¿Qué estrategias tecnológicas y sociales fueron desplegadas por los grupos humanos para ocuparlas durante lapsos prolongados de tiempo? ¿En qué medida la presencia de un grupo de personas podía transformar los paisajes y su capacidad de ofrecer agua? La respuesta a estas preguntas requiere integrar la información arqueológica y etnográfica con evidencias provenientes de las ciencias ambientales, particularmente aquellas relacionadas a la geomorfología, hidrología y ecología de los paisajes de dunas.

\section{2. Área de estudio}

De las diversas "Travesías" que caracterizan la Diagonal Árida Sudamericana, en este trabajo nos centramos en la conocida como Travesía Puntana, desarrollada en el sur de la provincia de San Luis (Figura 1), ya que allí convergen actualmente in- 


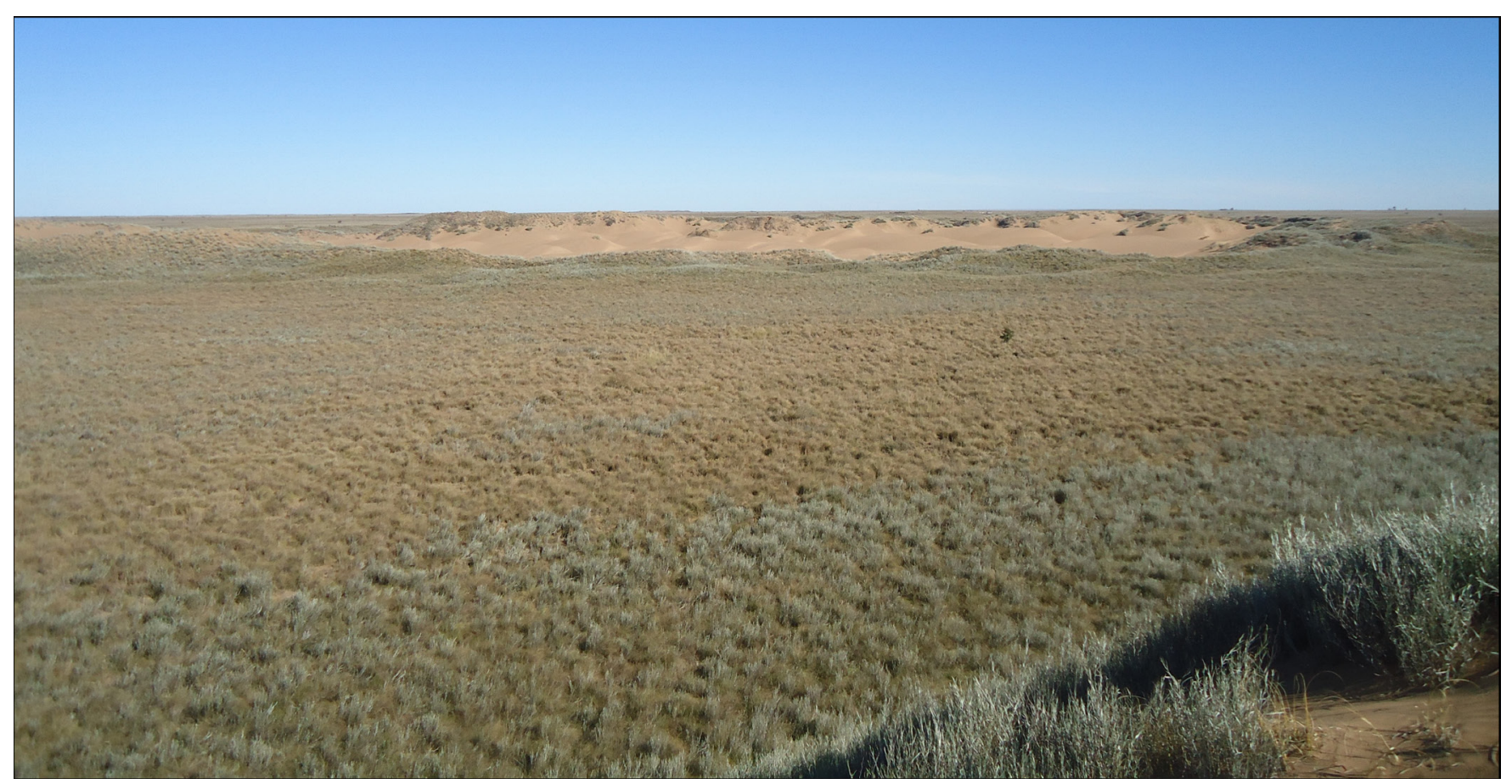

Figura 2 Paisaje característico de la Travesía Puntana. En el interior de la duna visible al fondo (Médano de la Primavera) se identificó material arqueológico en los sitios La Primavera 1, 2 y 3 (véase Heider, 2015).

vestigaciones de distintas áreas del conocimiento con un foco común en los paisajes de dunas. De modo complementario, se incorporan evidencias de la denominada Travesía Grande, en su porción del noreste de la provincia de Mendoza (Figura 1). Nos apoyamos para esto en un conjunto de características que les son comunes a las dos: (a) su cercanía espacial, (b) su registro arqueológico con algunas características generales semejantes en diferentes periodos de su desarrollo histórico, (c) su conexión en momentos de ocupación colonial temprana, (d) la trayectoria histórica homóloga seguida por los grupos locales (Rankülches y Huarpes, respectivamente) una vez consumada la incorporación de sus territorios al Estado Nacional hacia fines del siglo XIX.

\section{Contexto ambiental y climático}

El río Desaguadero discurre cerca del límite entre ambas travesías estudiadas y constituye un sistema fluvial activo, producto, fundamentalmente, de los aportes hídricos de la Cordillera de los Andes, a partir de diversos tributarios como son los ríos Bermejo, San Juan, Mendoza y Tunuyán (Figura 3). La cuenca hídrica del sistema Desaguadero-Salado presentaba un régimen principalmente estival, por el aporte de deshielos y las precipitaciones de verano, pero actualmente se encuentra fuertemente alterada y controlada por la acción antrópica en el piedemonte andino, debido a la presencia de obras de regadío y centrales hidroeléctricas. Se destaca la ausencia de redes de drenaje integradas dentro de las Travesías de San Luis y Mendoza (i.e. Font y Chiesa, 2015; Chiesa et al., 2015).

Climáticamente, las regiones aquí analizadas corresponden a una zona templada con condiciones semi-áridas a áridas, donde las precipitaciones tienen medias anuales en torno a los $700 \mathrm{~mm}$ en el este y los $100 \mathrm{~mm}$ en el noroeste (Servicio Meteorológico Nacional, 1992). Existen zonas de precipitaciones mínimas que se encuentran ubicadas en las regiones orientales y occidentales de la DAS, la cual limita los sectores dominados por el anticiclón del Atlántico sur, al este, y del anticiclón del 

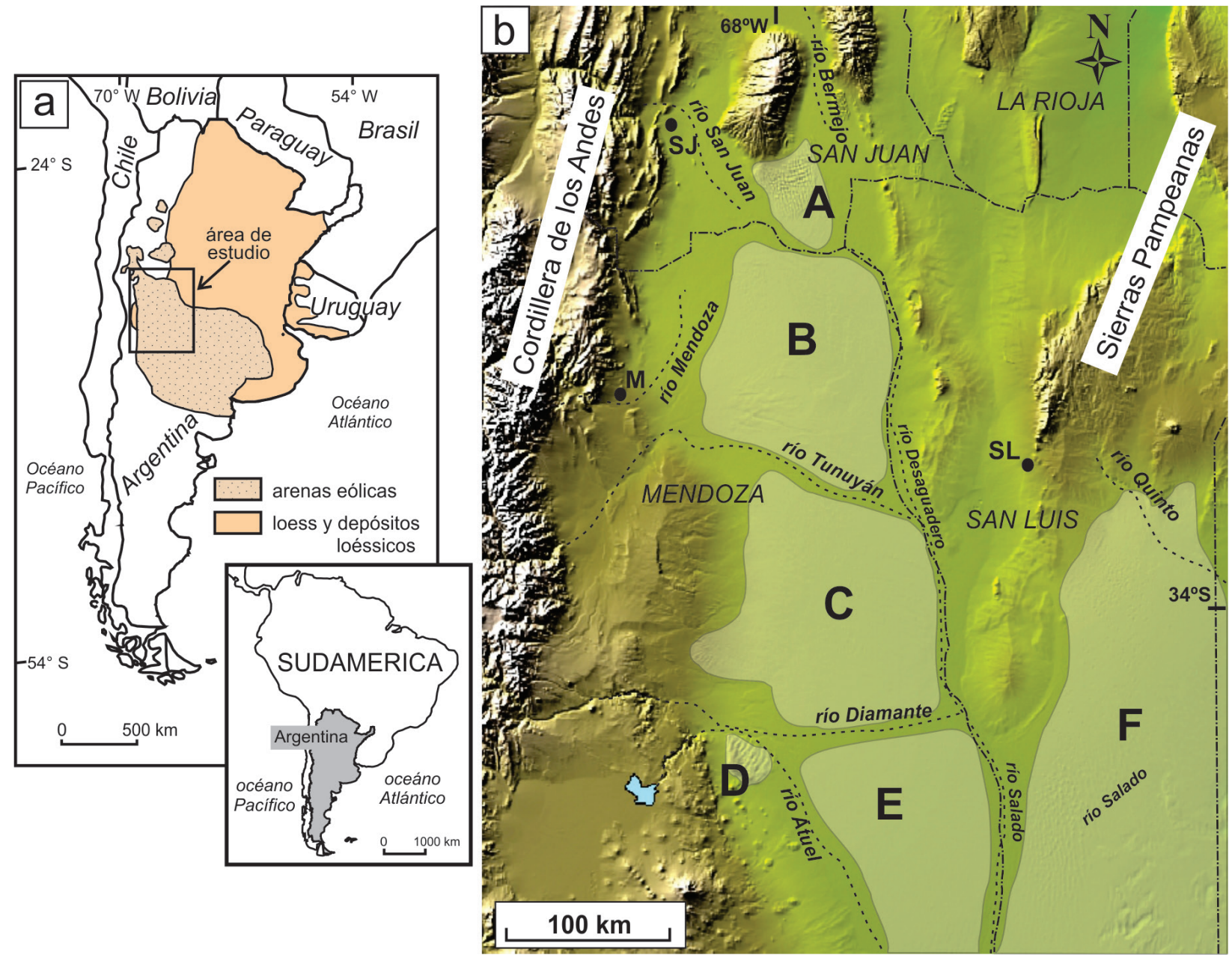

Figura 3 (a) Distribución de arenas eólicas y loess-depósitos loéssicos de Argentina (modificado de Zárate, 2003); (b) Principales campos de dunas del oeste de Argentina y su relación con la Cordillera de los Andes y las Sierras Pampeanas: -A- Médanos Grandes, -B- Médanos de Telteca, -C- Médanos de Tunuyán, -D- Médanos de Picardo, -E- Médanos Pampa de la Varita, -F- Médanos de San Luis (modificado de Tripaldi y Forman, 2007).

Pacífico sur, al oeste (Bruniard, 1982). En ambas travesías las precipitaciones ocurren fundamentalmente durante la temporada estival, asociadas al dominio Atlántico, debido a los aportes de humedad desde la región amazónica, transportados por la corriente en chorro meridional de capas bajas (Chaco Jet) (Garreaud et al., 2009). La Travesía Grande presenta, además, influencia del dominio Pacífico, por los aportes hídricos superficiales y subterráneos que provienen de la región cordillerana, donde la recarga está dominada por lluvias y nevadas invernales (Garreaud et al., 2009).

Desde el punto de vista biogeográfico, la Travesía Puntana y la Travesía Grande están ubicadas, respectivamente, en las provincias fitogeográficas Pampeana, con predominio del pastizal pampeano, y Monte, caracterizado por vegetación xerofítica (Cabrera, 1976; Soriano, 1992; Villagra y Roig, 1999, entre muchos otros).

\section{Antecedentes paleoambientales}

La DAS es una región de transición entre los dominios de los anticiclones del Atlántico y Pacífico sur, razón por la cual ha atraído el interés de investigadores en paleoambiente, paleoecología y paleoclima del Cuaternario. Allí se observa una 
marcada heterogeneidad ambiental a nivel local y condiciones climáticas que, en líneas generales, podrían describirse como opuestas al este y oeste de la DAS, es decir, entre la Travesía Puntana de San Luis y la Travesía Grande de Mendoza.

En el caso de San Luis, los estudios palinológicos y sedimentológicos de Salinas del Bebedero (-34.5 ${ }^{\circ}$, $-68.3^{\circ}, 670 \mathrm{msnm}$, Figura 1) sugieren un nivel lacustre máximo para los ca. $12000-13000 \mathrm{cal}$ años AP y su progresiva disminución hasta los niveles actuales en $c a .3600$ cal años AP (Rojo et al., 2012). Hacia el este, las secciones estratigráficas provenientes de campos de dunas y mantos eólicos $\left(-33.5^{\circ},-65.5^{\circ}, 500 \mathrm{msnm}\right.$, Figura 1) indican depositación dominantemente eólica entre $c a .12000$ y 1000 AP (cronología por luminiscencia, edades anteriores al AD 2000), favorecida por una cubierta de vegetación menor a la actual e interpretada como producto de precipitaciones significativamente más bajas que las contemporáneas (Forman et al., 2014). En esta misma área, los registros lacustres muestran cuerpos de agua incipientes en las interdunas hacia los $c a .1500-900 \mathrm{cal}$ años AP, los cuales evolucionaron a lagunas someras con fases húmedas y secas (Vilanova et al., 2015, 2017). Por su parte, para las planicies de Mendoza, los análisis polínicos realizados en Gruta del Indio $\left(-34.5^{\circ}\right.$ y -68.2, 670 msnm, Figura 1) muestran el predominio de vegetación de Monte durante el Holoceno medio a tardío (Markgraf, 1989). Por su parte, estudios sedimentológicos en sucesiones aluviales del piedemonte andino $\left(-33^{\circ},-34^{\circ} \mathrm{S}, 1000-850\right.$ $\mathrm{msnm}$ ) indican el predominio de sedimentación en sistemas fluviales, entrelazados arenosos durante la transición Pleistoceno-Holoceno y el Holoceno temprano, y luego en sistemas sinuosos asociados a eventos más frecuentes de incisión, durante el Holoceno medio a tardío (Mehl et al., 2012). Esta mayor frecuencia de erosión fluvial es interpretada como producto de condiciones regionales de mayor aridez que la actual en las planicies, junto con descargas significativas desde las áreas cordilleranas (Mehl et al., 2012). Las condiciones para el Holoceno medio y tardío para las planicies de Mendoza sugieren una disminución en las lluvias de verano y aumento de la temperatura entre 8500 y 5000 años AP; aumento de las precipitaciones invernales y disminución térmica media entre 5000 y 3000 años AP, y el establecimiento de condiciones climáticas modernas en 3000 años AP (Markgraf, 1989; Cioccale, 1999; Zárate, 2006).

\section{Análisis multidisciplinario de Las Travesías}

\subsection{LOS GRUPOS HUMANOS EN LAS TRAVESÍAS}

Las fuentes etnográficas tempranas sobre Las Travesías del centro-oeste de Argentina son escasas y, al mismo tiempo, espacialmente fragmentarias (véase Prieto y Abraham, 2000; Prieto y Chiavazza, 2006; Calderón, 2015; Chiavazza, 2015; Pastor y Boixados, 2016; García, 2017; Heider, 2017). De manera similar, las investigaciones arqueológicas presentan vacíos en cuanto a las áreas estudiadas y las problemáticas abordadas, con lapsos de más de 50 años sin estudios sistemáticos (i.e. Vignati, 1940; Cahiza, 2000; García-Llorca y Cahiza, 2007; Berón, 2013; Heider y Curtoni, 2016; García, 2017). Aun así, es posible presentar una reseña breve sobre la información arqueológica disponible.

Para finales del Holoceno temprano se observa un proceso de exploración y colonización común, ligado a un proceso pan-andino macrorregional (García, 2010; Cortegoso, 2014; Rivero y Heider, 2017, entre otros). Asociadas al Holoceno medio, se observan evidencias de la colonización de algunos espacios ecológicamente favorables (principalmente en las Sierras Pampeanas), que han generado una importante discusión acerca de la baja señal de ocupación humana en el registro arqueológico del centro-oeste (García, 2005; Gil et al., 2005; Zárate et al., 2005, entre otros). En el Holoceno tardío se verifican importantes cambios, con procesos de intensificación en la mayor parte de las áreas. Asimismo, para el piedemonte andino y las Sierras Pampeanas se registra la incorporación de recursos domesticados en dife- 
rentes proporciones, lo que modificó los patrones de organización y ocupación del espacio, creando trayectorias históricas divergentes (i.e. Cahiza, 2002, 2003; Cahiza y Ots, 2005; Gil, 2005; Gasco et al., 2011; Chiavazza, 2012; Medina et al., 2017). Para los sectores áridos de Las Travesías, los recursos silvestres fueron el principal componente de la dieta, en un contexto de economía de cazadores-recolectores (en ocasiones también pescadores) con baja densidad demográfica y alta movilidad, en comparación con los sectores vecinos. En este sentido, no se ha postulado la producción de recursos domesticados, sino hasta momentos posteriores al contacto hispano-indígena (Gil, 2005; Chiavazza, 2007, 2012, 2015; Heider, 2015, 2017; Heider y López, 2016, entre otros).

Una mirada distribucional (sensu Ebert, 1992) y biogeográfica de uso del espacio (i.e. Veth, 1989; Borrero, 1989-1990, 1994-1995; Anderson y Gillam, 2000) en Las Travesías indica una ocupación efectiva del espacio para el Holoceno tardío. Un dato relevante en relación con esto es la recurrencia en la utilización de algunos elementos del paisaje. Destacamos algunos ejemplos en este sentido. En el sector limítrofe entre las provincias de Mendoza y San Juan se verifica un patrón de superposición en las ocupaciones en el entorno de las Lagunas de Guanacache. Allí, García Llorca y Cahiza (2007) proponen la reocupación de sectores con rasgos topográficos característicos (e.g. zonas elevadas no inundables, médanos y bordos en las costas de lagunas). Esa superposición les permite postular (siguiendo a Schlanger, 1992) que algunos sectores constituirían lugares "persistentes". Un contexto similar fue propuesto para las márgenes del río Tunuyán por Ots y colaboradores (2015). La ocupación prehistórica del sector muestra un patrón de asentamiento en médanos, con una distribución de tipo agregada o agrupada correspondiente a pequeñas comunidades con un nivel bajo de integración (Ots et al., 2016). En la zona de bañados de la cuenca baja del río Mendoza también se verifica un uso del espacio similar (Chiavazza, 2015). En un contexto excavado (sitio Tulumaya) se caracterizó un sistema de asenta- miento-subsistencia que habría resultado sensible a las fluctuaciones climáticas entre el $c a .1000$ a 300 AP (Chiavazza, 2010). Aunque la tecnología lítica muestra similitudes con la Precordillera, los estudios zooarqueológicos y arqueobotánicos evidencian el uso de recursos silvestres con ausencia de especies domésticas, de manera opuesta a lo que sucede en la mencionada región (Gasco et al., 2011).

\subsection{ARQUEOLOGÍA EN LA TRAVESÍA PUNTANA}

Las investigaciones arqueológicas en La Travesía Puntana fueron incluidas dentro de un marco geográfico más amplio, esto es, dentro de la subregión arqueológica de Pampa Seca (Heider, 2015). Las preguntas a partir de las cuales se investigó estuvieron fuertemente condicionadas por la escasez de estudios previos, y por la necesidad de crear un cuerpo inicial de datos acorde a los requerimientos actuales y a las posibilidades de contrastación de estos con aquellos provenientes de regiones vecinas. Los estudios de la organización de la tecnología fueron utilizados conjuntamente con modelos de optimización y biogeográficos para abordar las problemáticas propias de los cazadores-recolectores de zonas áridas y semi-áridas (Bettinger, 1991; Nelson, 1991; Gamble, 1993; Borrero, 1994-1995, entre muchos otros). Un énfasis especial estuvo puesto en el estudio de las materias primas. En este sentido, el análisis de la base regional de recursos líticos (sensu Ericson, 1984) permitió constatar la presencia de rocas de origen local en el área. Se detectó, además, la presencia de materiales líticos procedentes de sectores que pueden ser considerados próximos cercanos, como Cerro Varela o Las Sierras Centrales (provincias de San Luis y Córdoba) y otros muy distantes, como la Cordillera de Los Andes y las Sierras de Tandil (Heider, 2016). La principal hipótesis de investigación planteó que, en el interior del área de estudio, el agua y la materia prima lítica constituyeron dos recursos que fueron determinantes en la toma de decisiones de los grupos locales (Heider, 2015, 2016). En este sentido, las problemáticas relacionadas con los 
recursos hídricos fueron abordadas siguiendo los postulados de un amplio abanico de investigaciones desarrolladas en grupos cazadores-recolectores de zonas áridas y semiáridas (i.e. Gould, 1991; Kelly, 1995; Bird y Bird, 2005).

En el contexto descripto, se utilizaron metodologías propias de la Arqueología Distribucional (sensu Ebert, 1992) para relevar el territorio. Se realizaron transectas longitudinales en cuatro tipos de geoformas seleccionadas (dunas, lagunas permanentes y temporarias, río y arroyos, positivos morfológicos), así como en espacios intermedios entre dichas unidades. Si tenemos en cuenta solo a La Travesía Puntana, dentro del territorio total estudiado, se observa una recurrencia notoria del uso del espacio. El $100 \%$ de los sitios arqueológicos $(n=64)$, así como los hallazgos aislados $(n=$ 123) fueron identificados en dunas activas o estabilizadas (Figura 2). La variedad en la densidad de hallazgos realizados no permite diferenciar sitios con actividades específicas de otros con actividades múltiples. Se observó que la mayor parte de los sitios $(\mathrm{n}=58)$ fue registrado en dunas que no tienen actualmente agua en superficie, identificándose evidencias de paleolagunas en solo ocho de ellas. Por otra parte, en los casos en que fueron registrados sitios asociados a cuerpos de agua, estos se presentaron siempre en el sector de acumulación de las hoyadas de deflación (Heider, 2015). Debido al déficit hídrico de la Travesía Puntana, el agua fue categorizada como un recurso crítico, determinante en el uso del espacio y la movilidad de los grupos cazadores-recolectores locales. En relación con esto, en las dunas se identificó la presencia de rocas sin rastros antrópicos y con pesos de más de $4 \mathrm{~kg}$ en algunos casos, lo cual indicaría una litificación del paisaje (Webb, 1993; Martínez, 2002 , entre otros), proceso que supone una conducta de anticipación de usos futuros. Para este tipo de ambientes, Kelly (1995), sobre la base de modelos de la ecología evolutiva, propone que los grupos pueden permanecer asentados en un lugar más tiempo del predicho, priorizando la seguridad por sobre la eficiencia. En definitiva, el reconocimiento, por parte de los grupos humanos locales, de estos espacios medanosos como favorables dentro de un área marginal permitió reducir el riesgo y la incertidumbre producida por la baja predictibilidad de las lluvias y, por lo tanto, su uso habría sido prolongado a través del tiempo (Heider, 2015, 2016, entre otros).

\subsection{GEOMORFOLOGÍA E HIDROECOLOGÍA DE LAS TRAVESÍAS}

Una fracción apreciable del territorio de Las Travesías está ocupada por depósitos arenosos producto de transporte eólico (Iriondo, 1990, 1999; Iriondo y Kröhling, 1995), comunes en toda la llanura pampeana. La amplia y diversa cubierta de estos depósitos en el centro de Argentina fue sistematizada por Zárate y Tripaldi (2012), quienes definieron ocho unidades eólicas sobre la base del tipo de depósitos, geoformas y contexto geológico-estructural. Las áreas aquí estudiadas, Travesía Puntana y Travesía Grande, se ubican en las unidades Campos de Dunas Occidentales y Campos de Dunas del Piedemonte Andino, respectivamente (Zárate y Tripaldi, 2012).

La Travesía Puntana comprende una parte de las serranías occidentales y la planicie medanosa. Las serranías occidentales tienen un relieve suave que aloja depósitos aluviales finos y, en menor medida, arenas y limos eólicos. La planicie medanosa contigua incluye una diversa variedad de dunas entre las que se destacan grandes unidades de deflación de forma subcircular, de hasta $2 \mathrm{~km}$ de diámetro y $20 \mathrm{~m}$ de desnivel entre las zonas de deposición periféricas y la base de la cubeta interna (Tripaldi y Forman, 2007). Hacia el noreste del campo de dunas, un gran número de estas áreas de deflación está ocupado por lagunas someras y permanentes, desarrolladas por la intercepción del nivel freático con la cubeta de deflación.

La Travesía Grande se corresponde con diversos campos de dunas que cubren la amplia planicie que se extiende desde el piedemonte andino (Figura 1). La cubierta de dunas presenta, en varios sectores, una estrecha asociación con ríos andinos que tributan al sistema Desaguadero-Salado (los ríos 
San Juan, Mendoza, Tunuyán y Diamante, Figura 3), así como abanicos terminales, arroyos efímeros y paleocauces (Figura 1). Geomorfológicamente, resulta un ambiente eólico complejo, con diversas morfologías de dunas (Krömer, 1996; Tripaldi, 2002, 2010; Tripaldi y Limarino, 2004; Tripaldi y Forman, 2007, entre muchos otros). Entre las geoformas dominantes en la planicie oriental se reconocen dunas longitudinales de baja altura (menos de $3 \mathrm{~m}$ ) y elongadas en sentido NO-SE, junto con grandes dunas de deflación (blowout dunes, McKee, 1979). En algunos sectores (e.g. Médanos Grandes, Médanos de los Naranjos, Médanos de Picardo) aparecen dunas complejas que superponen diferentes morfologías y orígenes y adquieren mayores dimensiones (Tripaldi, 2002, 2010).

Los campos de dunas albergan con frecuencia acuíferos freáticos relativamente poco profundos. En la medida en que estas aguas subterráneas se aproximan a la superficie aparecen en los puntos más bajos del paisaje, zonas de mayor densidad y productividad de la vegetación, áreas de suelo húmedo o temporariamente encharcado y, finalmente, cuerpos de agua permanentes (Compagnucci et al., 2002; Wang et al., 2004; Scanlon et al., 2005; Eamus et al., 2006, entre otros). Los campos de dunas de la Travesía Puntana despliegan un profuso sistema de lagunas en su porción oriental $\left(33.5^{\circ}\right.$ a $34.3^{\circ} \mathrm{S}$ y $65.2^{\circ}$ a $\left.65.4^{\circ} \mathrm{O}\right)$. Ocupadas por agua dulce y con profundidades variables, muchas de estas lagunas superan los 5 metros de profundidad en la actualidad. Las mismas han mostrado descensos de unos 2 metros en tiempo histórico, coincidentes con el fin del último período de sequía prolongada a finales de la década del sesenta (Bogino y Jobbágy, 2011). Sin embargo, las fotografías aéreas de ese período seco, así como la presencia de corredores de árboles (¿rastrilladas indígenas?) dentro de una matriz de pastizal puro como indicadores de tránsito animal conectando lagunas (véase León y Anderson, 1983) y la toponimia del paisaje (Mollo, 2017), indican que muchas de estas lagunas son de carácter permanente. Los muestreos de sedimentos realizados en dos de estos cuerpos de agua (Los Pocitos y Primera La- guna) muestran que han atravesado un estado de cuerpo lacustre permanente durante, al menos, los últimos 600 y 1600 años respectivamente (Vilanova et al., 2015, 2017).

Cabe preguntarse cómo es posible que en un paisaje de llanura y clima semiárido en el cual la evaporación a la atmósfera supera ampliamente a los aportes de la precipitación, pueda encontrarse agua libre permanente y dulce, especialmente a gran distancia de los cordones montañosos andinos. Concurren aquí tres aspectos naturales de los paisajes de dunas: (a) la gran permeabilidad de los materiales arenosos (Hillel, 1998) y la dificultad que encuentran las raíces de las plantas para hacer un uso exhaustivo del agua en ellos (Sperry et al., 1998), lo cual lleva a que una fracción de las lluvias alcance el manto freático. Aun cuando escaso, este flujo es apreciable y se detecta en condiciones climáticas muy áridas, por ejemplo, en el campo de dunas de Telteca, con sólo $150 \mathrm{~mm} /$ año de precipitación (Jobbágy et al., 201 1). (b) Esta capacidad de recarga freática, combinada con la disposición regionalmente plana pero localmente ondulada del paisaje, lleva a que en los puntos más bajos el agua se acerque a la superficie. Una gran área de recarga (esencialmente todo el campo de dunas) y un área de evaporación pequeña (solo las zonas de lagunas y los bajos con vegetación que acceden a la capa freática) permiten que el sistema mantenga su balance. (c) La existencia de flujo horizontal subterráneo de agua, favorecido por la alta conducción del material arenoso, permite que los cuerpos de agua no se salinicen indefinidamente por evaporación y mantengan una composición dulce relativamente estable (Figura 4).

Se plantea aquí como hipótesis que la formación y permanencia de lagunas y su papel como oasis dentro de las travesías puede ser favorecido por la presencia de grupos humanos y fauna, entre esta última principalmente animales introducidos (ganado europeo) y ungulados (Lama guanicoe). Esto generaría una retroalimentación positiva, en la que el oasis atrae a ocupantes, y estos a su vez aseguran su existencia e incluso su ampliación a partir de las transformaciones ecológicas y geomorfológicas 

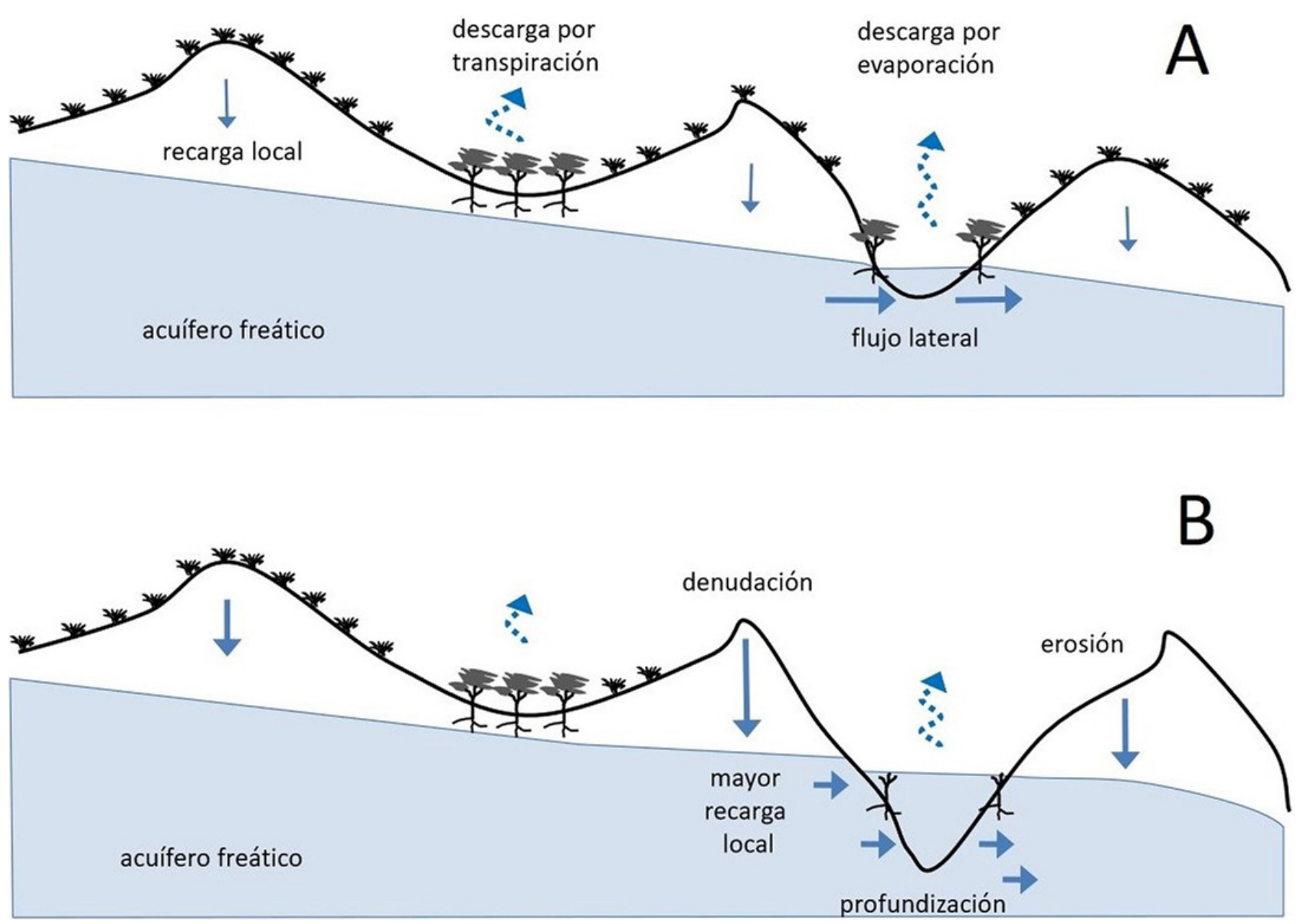

Figura 4 Modelo de Balance Hídrico en las dunas: (A) Paisaje con alta cubierta vegetal y baja erosión. (B) Paisaje con alta erosión en las dunas y denudación del terreno.

que imponen. Los mecanismos de esta retroalimentación incluyen dos procesos clave, que son el aumento de la recarga hidrológica y la erosión y profundización de la cubeta de la laguna, ambos favorecidos por el disturbio de la cubierta vegetal y el pisoteo que generan los asentamientos humanos y la actividad de herbívoros. En el primer proceso, la recarga hidrológica se ve aumentada como resultado de la denudación total o parcial de la zona periférica a la laguna. En paisajes áridos o semiáridos normalmente la totalidad de la precipitación es evapotranspirada y no hay recarga de aguas subterráneas. Sin embargo, superado cierto nivel de perturbación de la cubierta vegetal, el consumo y transpiración de agua por las plantas merma a tal punto que comienza a generarse un flujo de agua excedente hacia las napas freáticas. En paisajes de travesía, bajo un clima aún más árido que el de San Luis, se ha observado este fenómeno y se ha documentado la presencia de flujos de recarga significativos en bajos intermedanosos ocupados por puestos en los que el pastoreo caprino y la extracción de madera han generado una denudación intensa (Aranibar et al., 2011; Meglioli et al., 2014) y, en consecuencia, el inicio de un flujo de recarga subterránea capaz de sostener niveles freáticos más elevados (Jobbágy et al., 2011). De esta forma, se especula aquí que la ocupación humana y animal de las lagunas del paisaje arenoso de San Luis podría haber disparado procesos de denudación que aumentaran la recarga freática y elevaran el nivel de las napas localmente y, consecuentemente, de la laguna. Se suma a este proceso otro asociado también a la denudación, pero tal vez también favorecido intencionalmente por las poblaciones humanas, que es el de la profundiza- 
ción de las holladas de las lagunas. En este caso, la denudación producida en épocas secas en que las lagunas tienen bajo nivel y las napas están más profundas, favorecería la erosión por el viento y el transporte del material del centro de la laguna hacia alguno de sus bordes, incrementando el volumen y deprimiendo el nivel de fondo. A estos procesos no intencionales o pasivos disparados para la concentración humana y animal que podría intensificarse en años secos, debe sumarse la excavación intencional o activa del fondo de lagunas secas para asegurar la presencia de agua libre. Ante lagunas que se retraen, la excavación de sus fondos para acceder a la napa freática puede ser una estrategia clave de supervivencia, y la misma ha sido confirmada en el pasado reciente por trabajos etnográficos (Greslebin, 1961; Heider, 2017). En resumen, tanto por la elevación del nivel freático como por la profundización del nivel del fondo de las lagunas, la denudación y el disturbio de la vegetación, la erosión y la excavación intencional pueden ser las fuerzas que sostienen una retroalimentación entre el oasis y sus usuarios, opuesta a las fuerzas más comúnmente invocadas de retroalimentación negativa en la que los usuarios agotan o destruyen recursos, imposibilitando su uso posterior. $\mathrm{Al}$ caso anterior puede sumarse otro propio de terrenos con suelos más finos e impermeables. Actualmente en estas zonas las reservas de agua consisten en represas que interceptan el flujo superficial que acompaña a las tormentas fuertes y lo almacenan en una laguna artificial. Pequeñas depresiones naturales pueden haber cumplido esta función en forma natural, y el pisoteo en su interior, junto al efecto de abastecimiento que generan aquellos caminos de acceso ubicados aguas arriba del espejo de agua, puede explicar otro fenómeno de retroalimentación positiva entre el oasis y sus usuarios. En la zona de estudio las represas actuales son abastecidas principalmente por los caminos trazados espontáneamente por el ganado (Magliano et al., 2015).

\section{Discusión}

Las Travesías ubicadas en el centro de la Diagonal Árida Sudamericana fueron caracterizadas desde una perspectiva eurocéntrica al momento del arribo de los españoles, adjetivándolas como paisajes duros, carentes de agua y prácticamente intransitables. En un mismo sentido, el proceso final de expansión del Estado Nacional argentino sobre buena parte de estos territorios implicó la utilización explícita de términos con una connotación negativa (Auza, 1980) en palabras del presidente Nicolás Avellaneda “... suprimir a los indios y ocupar las fronteras no implica en otros términos sino poblar el desierto..." (Bartolomé, 2004). Las evidencias arqueológicas sugieren algo diferente; los pueblos originarios exploraron el centro de la DAS desde finales del Holoceno temprano. Más aún, siendo actualmente estos parajes los menos densamente poblados del centro de Argentina, siguen aún hoy habitados por integrantes de las diferentes etnias como son los Rankülches y Huarpes. Este hecho no debería resultar sorprendente si se piensa que los grupos humanos prefirieron, desde hace más de 30000 AP, poblar voluntariamente ambientes desérticos, como así también persistir en la ocupación de paisajes que sufrieron procesos de aridización (Veth, 2005 y autores allí citados).

El análisis multidisciplinario aquí presentado, convergente en una perspectiva geoarqueológica, muestra una notoria relación entre el uso del espacio de los grupos humanos y los paisajes de dunas, expresada en la reocupación de los mismos dentro de Las Travesías Puntana y La Travesía Grande. Hasta el presente no se han abordado específicamente las posibles características que convirtieron a las mismas en la principal geoforma donde se registran sitios arqueológicos en el centro de la DAS, aun cuando diversos investigadores las identifican como sectores con abundancia de hallazgos arqueológicos, catalogándolas incluso como lugares "persistentes" (García-Llorca y Cahiza, 2007; Chiavazza, 2012; Heider 2015). Se propone aquí entender a las áreas de dunas como verdaderos 
"eco-refugios" (en términos de Núñez et al., 1999 y trabajos allí citados). Estos autores utilizan ese concepto para explicar la ocupación en la Quebrada de Puripica (norte de Chile), entendiendo a ese sector del paisaje como un lugar excepcional a partir de sus características geomorfológicas, que permitieron la concentración de agua (y por lo tanto vegetación y fauna), creando un locus favorable en un escenario árido (Grosjean et al., 1997; Núñez et al., 1999, entre otros). Del mismo modo, las dunas ubicadas en las Travesías Puntana y Grande son capaces de retener agua en acuíferos libres aun en condiciones semiáridas y áridas. Esta condición se mantuvo incluso en momentos más áridos que los actuales, como son las fases de sedimentación eólica reconocidas en el registro del Holoceno. Por lo tanto, la ocupación humana de esos "espacios persistentes" podría resultar, hasta cierto punto, independiente de las condiciones climáticas imperantes. Esto sería consecuencia de que la recarga de las dunas no depende completamente del entorno cercano o lejano (por ejemplo, el caudal superficial o subterráneo de los ríos andinos y la presencia de agua en las lagunas de San Luis o los humedales de Mendoza/San Juan). La presencia de un reducido volumen de lluvia sería suficiente para crear pequeñas lagunas efimeras y, luego de la percolación, conformar reservas plausibles de ser utilizadas por las poblaciones durante el Holoceno (Figura 5).

En este punto es entonces necesario mencionar y discutir sobre las variantes tecnológicas que permitieron a los grupos humanos cosechar agua en la DAS. Los sitios arqueológicos que se ubican en médanos sufren una serie de procesos post-depositacionales (en términos tafonómicos) que crean, por deflación, una superposición de materiales, los cuales pueden pertenecer, incluso, a ocupaciones separadas por miles de años (Bailey, 2007). Los mismos procesos contribuyen a la destrucción de posibles rasgos arquitectónicos, como paredes de ranchos o estructuras de toldos. Por esto, la observación de rasgos clasificables como estructuras tecnológicas para cosechar agua es muy poco probable. En relación con esto, no se tienen registros de publicaciones de corte netamente arqueológico en donde se evidencien estructuras utilizadas para cosechar agua en Las Travesías. Por el contrario, sí existen menciones de cronistas y viajeros sobre la existencia de pozos como rasgo tecnológico orientado a la colecta. El viajero Luis de La Cruz intentó cruzar, durante el año 1806, desde el fuerte de El Ballenar (Concepción, Chile) hasta Buenos Aires (Argentina) atravesando durante el viaje La Travesía del Oeste Pampeano. Durante el trayecto, realizó un conjunto de menciones sobre pozos de agua en las tolderías donde los nativos (e incluso él mismo y sus compañeros de viaje) bebían.

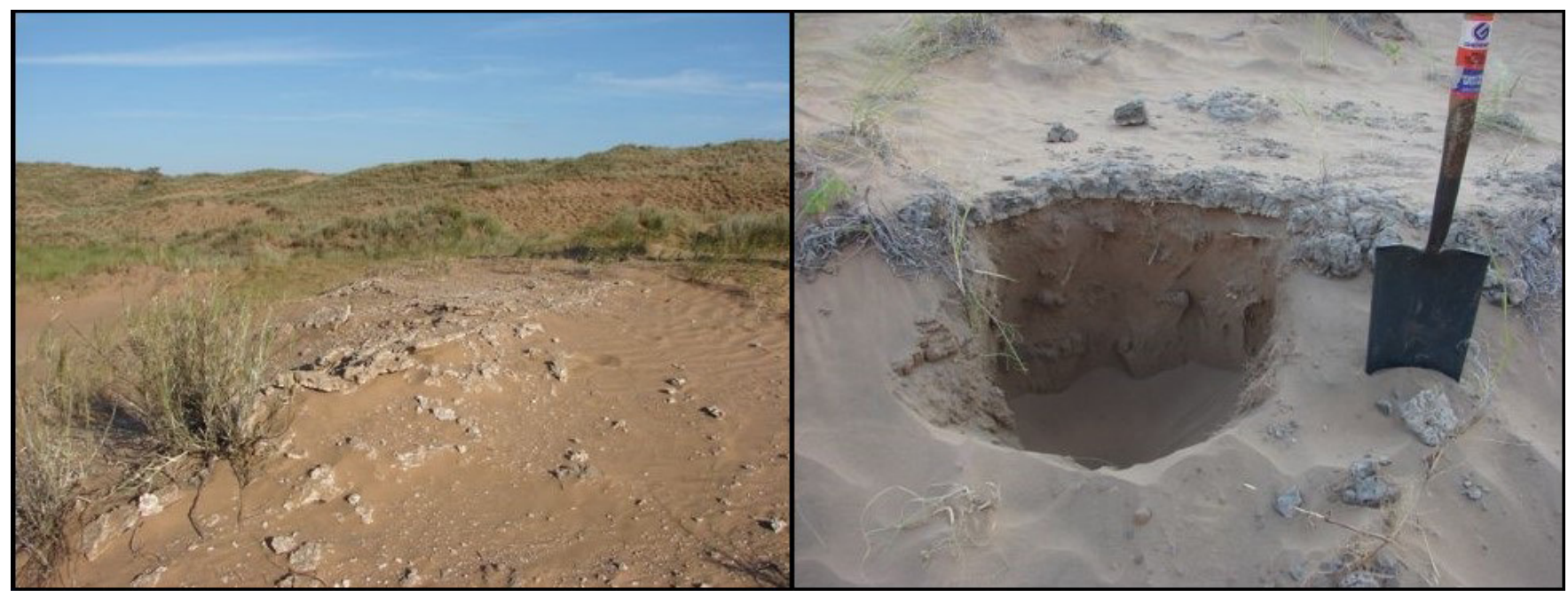

Figura 5 Laguna efímera en la Travesía Puntana. Fotografías cortesía de Daniela Storchi Lobos. 
De las catorce referencias totales en este sentido, transcribimos las dos que ilustran de mejor modo a los pozos como rasgo tecnológico. La primera explicita la tecnología sencilla que se necesitaba para hacerlos, utilizando únicamente un palo puntiagudo: "Las aguas de todas las poblaciones son de pozos hecho a calla; pero en cualquiera parte que se cave, a las tres cuartas, brota a borbotones, y no es mala." (de la Cruz, 1969: 153). La segunda señala las diferentes calidades que percibe entre el agua subterránea (surgente en el pozo excavado por los Rankülches) y la de las lagunas superficiales que lo rodeaban: "... a la una y media llegamos al lugar de Guaguaca, que es un medanillo con varios cerrillos bajos, entre los cuales hay tres lagunas permanentes, dos de agua amargosa, una buena, y un pozo que es la mejor que visto, y más clara desde Chadileubú..." (de la Cruz, 1969: 178). Del segundo cronista, Santiago Avendaño, y sus valiosas memorias obtenidas durante su cautiverio con los indios de Las Pampas, se destacan nuevamente dos puntos. En un sentido similar a lo observado por de la Cruz sobre la ubicación y calidad del agua en los pozos menciona que "Yo conocía unos tres pocitos de agua a pocas varas de la laguna (la laguna era de aguas amargas). Me acerqué a uno de ellos en los que di de beber a los caballos, como lo permitía la urgencia. Yo mismo también tomé agua y salí buscando la senda..." (Avendaño, 2012: 209). La segunda destaca, interpretamos, la necesidad de saberes tradicionales para seleccionar correctamente el punto donde excavar: "En 1845 alcancé a ver unos siete pozos que los cristianos habian hecho cuando fueron a invadir a los indios, desesperados en la travesía por la sed; y si lograron sacar agua no ha sido para satisfacer la necesidad que tenían de ella, porque los pozos eran hechos en lomadas guadalosas y la tierra era muy seca..." (Avendaño, 2012: 130).

Como se mencionó, no hay registro arqueológico compatible con pozos en Las Travesías. Sin embargo, existen publicaciones que señalan su presencia en ambientes similares de otros puntos del planeta. En el centro de Argentina se logró identificar un único ejemplo arqueológico perteneciente a grupos cazadores-recolectores en el sitio Paso Otero 4 (provincia de Buenos Aires). El hoyo fue excavado en las cercanías al cauce del río Quequén Grande y fue asociado con un fechado de $c a .8500$ años AP. Aunque este ambiente no corresponde a un paisaje árido o semi-árido, dicho rasgo se vincula con un momento ambiental de mayor aridez local (Álvarez et al., 2013). El pozo fue interpretado como estructura para enfrentar la escasez de agua en un sentido similar al utilizado por los habitantes de las planicies norteamericanas (Gutiérrez y Martínez, 2015). Es justamente allí, en las Grandes Planicies del centro de Estados Unidos, donde surgieron evidencias notorias en el registro arqueológico sobre la utilización de pozos en el continente americano. En diversos trabajos se propone que esa fue la respuesta de los grupos locales al aumento de la aridez en el Hipsitermal, al menos durante un período que abarcó ca. 3000 años (Meltzer y Collins, 1987; Meltzer, 1991, 1999, entre otros). Otros ejemplos relacionados con desiertos arenosos fueron estudiados en Australia, donde Bayly (1999) realiza una valiosa revisión de cómo los pueblos indígenas lograron obtener agua en las regiones desérticas. El autor revisa tanto ejemplos arqueológicos como etnográficos e identifica diferentes modalidades. Para nuestro caso de estudio son relevantes los "Soaks (native wells)", verdaderos huecos excavados en sedimentos permeables o en los cauces secos de los ríos e identificados por los viajeros como "commonly holes dugin to sand" (Bayly, 1999: 20). La profundidad no superaba los 4 o 5 metros, con un promedio de aproximadamente 1.5 metros y podían estar llenos con palos o arena para evitar la evaporación y detener animales que pudieran beber o ensuciar el agua. Por otra parte, el autor, retomando a Gould (1969), le da un gran valor al papel de la cultura y el conocimiento tradicional para ubicar los suministros de agua, como así también su volumen aproximado.

\section{Consideraciones Finales}

A partir del registro arqueológico actualmente disponible se puede observar una coincidencia, en diferentes regiones de Argentina, sobre un proceso de exploración inicial del territorio a partir de 
grupos pequeños y altamente móviles (con las dificultades que esto tiene para ser observado en el registro arqueológico), que desembocó luego en un aumento continuo en tamaño y complejidad (Gil, 2005; Borrero, 1994-1995; Belardi, 1996, entre muchos otros). $\mathrm{Al}$ parecer, la diferenciación entre la colonización y la ocupación efectiva en áreas marginales es más una consecuencia del tamaño de muestra y la visibilidad del registro arqueológico (así como los procesos tafonómicos) que de cambios en patrones de movilidad (Veth, 2005 y autores allí citados). Así, la ocupación en Las Travesías parece tener un comienzo en los últimos momentos del Holoceno temprano y un notorio aumento de la señal arqueológica recién para el Holoceno final, hacia los ca. 2500 AP. Como se mostró, las dunas tuvieron un importante papel en el uso del espacio, siendo persistentemente ocupadas por las poblaciones humanas debido, entendemos, a su valor como eco-refugios. Finalmente, y aun cuando no es el objetivo de este trabajo, debe mencionarse la importancia de las decisiones conductuales para entender abordajes futuros de ocupación en la DAS. Como menciona Veth (1989, 1995), los riesgos de los desiertos son reales y las medidas de mitigación han sido bastante extremas a escala mundial, incluido el abandono de territorios enteros durante sequías, en casos de conflictos o muerte (Gould, 1991; Kelly, 1995). Situaciones similares pueden haber tenido lugar en Las Travesías a diferentes escalas, con el abandono de pozos producto de la impericia de los cristianos mencionados por Avendaño (2012), una peste de viruela que mató a todos los habitantes de una toldería (de la Cruz, 1969 [1835]) o un fenómeno de aridez de escala regional como el planteado para parte del centro-oeste de Argentina (Gil et al., 2005). En definitiva, fueron también decisiones conductuales las que transformaron las dunas en eco-refugios debido a su capacidad para retener agua. Esa reocupación fue formando y transformando a esos espacios en lugares donde los grupos humanos pudieron obtener agua en forma segura, posiblemente a partir de una mejora en las condiciones del oasis, fruto de la retroalimentación positiva entre la ocupación y el aumento de la disponibilidad de agua en las lagunas.

\section{Agradecimientos}

Nuestro afecto y respeto a todos los habitantes de Las Travesías, los cuales nos recibieron en sus puestos y estancias. A los integrantes de los pueblos originarios por su apoyo y al gobierno de la provincia de San Luis por los permisos para investigar. Estos trabajos fueron financiados con los subsidios Agencia-SEGyT-Argentina (PICT-200382, PICT2007-01222); UBACyT (20620100100009 y 20620130100002). Agradecemos a María Clara Álvarez por la lectura crítica de este manuscrito. Los datos meteorológicos de Las Travesías fueron provistos por el Servicio Meteorológico Nacional. Finalmente, queremos agradecer a los dos evaluadores anónimos que, con sus comentarios, permitieron mejorar notoriamente este trabajo, así como al editor por sus comentarios y sugerencias.

\section{Referencias}

Álvarez, M., Alcaráz, A., Gutiérrez, M., Martínez, G., 2013, Análisis zooarqueológico del sitio Paso Otero 4 (partido de Necochea). Aportes a la discusión de los modelos de subsistencia de la región pampeana: Intersecciones en Antropología, 14, 383-398.

Anderson, D., Gillam, J., 2000, Paleoindian Colonization of the Americas: Implications from an Examination of Physiography, Demography, and Artifact Distribution: American Antiquity, 65, 43-66.

Athavale, R., Rangarajan, R., Muralidharan, D., 1998, Influx and efflux of moisture in a desert soil during a 1 year period: Water Resources Research, 34, $2871-2877$.

Auza, N., 1980, La ocupación del espacio vacío: de la frontera interior a la frontera exterior: 1876-1910, en Ferrari, A., Gallo, E. (eds.), La 
Argentina del ochenta al centenario: Buenos Aires, Editorial Sudamericana, 141-163.

Avendaño, S., 2012, Usos y costumbres de los indios de la pampa: Buenos Aires, El Elefante Blanco, 154 p.

Bailey, G., 2007, Time perspectives, palimpsest and the archaeology of time: Journal of Archaeological Science, 26, 198-223.

Bartolomé, M., 2004, Los pobladores del "desierto": Amérique Latine, Histoire et Mémoire. Les Cahiers, 10, 86-103.

Bayly, I., 1999, Review of how indigenous people managed for water in desert regions of Australia: Journal of the Royal Society of Western Australia, 82, 17-25.

Belardi, J., 1996, Cuevas, aleros, distribuciones y poblamiento, en Gómez-Otero, J. (ed.), Arqueología Sólo Patagonia: Puerto Madryn, Centro Nacional Patagónico, 43-48.

Berón, M., 2013, La arqueología del sector occidental de la región pampeana. Trayectoria y reposicionamiento respecto a la arqueología nacional: Revista del Museo de La Plata, sección Antropología, 13(87), $7-29$.

Berón, M., 2016, Dunes, hills, waterholes, and saltpeter beds: Attractors for human populations in western Pampa, Argentina: Quaternary International, 422, 163-173.

Bettinger, R., 1991, Hunter-Gatherers: archaeological and evolutionary theory, New York, Plenum Press, 224 p.

Bird, R., Bird, D., 2005, Human hunting seasonality in savannas and deserts, en Brockman, D., Van Schaik, C. (eds.), Primate Seasonality, Cambridge, Cambridge University Press, 243-266.

Bogino, M., Jobbágy, E., 2011, Climate and groundwater effects on the establishment, growth and death of Prosopis caldenia trees in the Pampas (Argentina): Forest Ecology and Management, 262, 1766-1774.

Borrero, L., 1989, Spatial heterogeneity in Fuego-Patagonia, en Shennan, S. (ed.), Archaeological Approaches to Cultural
Identity: Sydney, Unwin Hyman, 258-265.

Borrero, L., 1989-1990, Evolución cultural divergente en la Patagonia austral: Anales del Instituto de la Patagonia, Serie Ciencias Sociales, 19, 133-140.

Borrero, L., 1994-1995, Arqueología de la Patagonia: Palimpsesto, 4, 9-69.

Bruniard, E., 1982, La diagonal árida argentina: un límite climático real: Revista Geográfica, 95, 5-20.

Butzer, K., 1989, Arqueología: una ecología del hombre, Barcelona, Editorial Bellaterra, 180 p.

Cabrera, A., 1976, Regiones fitogeográficas argentinas, en Cabrera, A., Enciclopedia Argentina de Agricultura y Jardinería, Buenos Aires, ACME SACI, II (1),1-85.

Cahiza, P., 2000, Investigaciones arqueológicas e históricas del área lacustre de Guanacache, Lavalle, Mendoza: Cuaderno del Centro de Graduados, 5, 113-124.

Cahiza, P., 2002, Paleogeografía de las tierras bajas de Mendoza y San Juan: un acercamiento arqueológico a la ocupación del espacio de las comunidades agroalfareras (Siglos VIXVIII d.C.), en Actas Jornadas Guyanas de Geografia IX, Universidad Nacional de Cuyo, Mendoza, 12 p.

Cahiza, P., 2003, La Dominación inka en las Tierras Bajas de Mendoza y San Juan: Mendoza, Argentina, Facultad de Filosofía y Letras, Universidad Nacional de Cuyo, tesis doctoral, $408 \mathrm{p}$.

Cahiza, P., Ots, M., 2005, La presencia inka en el extremo sur oriental del Kollasuyo. Investigaciones en las tierras bajas de San Juan y Mendoza, y el Valle de Uco -República Argentina: Xama, 15-18, 217-228.

Calderón, A., 2015, Aquí vive Guanacache. Una Etnografía de la (re)producción étnica huarpe en San Luis, Argentina, Córdoba, Argentina, Universidad Nacional de Córdoba Departamento de Antropología, Facultad de Filosofia y Humanidades, tesis de licenciatura, $188 \mathrm{p}$. 
Canals-Frau, S., 1945, Los Huarpes y sus doctrinas. Un documento: Anales del Instituto de Etnografía Americana, 3, 61-91.

Canals-Frau, S., 1950, La población de Los Llanos: Anales del Instituto Étnico Nacional, III, 67-81.

Chiavazza, H., 2007, Cambios ambientales y sistemas de asentamiento en el árido normendocino. Arqueología en los paleocauces del río Mendoza: La Plata, Argentina, Facultad de Ciencias Naturales y Museo, Universidad Nacional de La Plata, tesis doctoral, $1262 \mathrm{p}$.

Chiavazza, H., 2010, Ocupaciones en antiguos ambientes de humedal de las tierras bajas del norte de Mendoza: sitio Tulumaya (PA70): Intersecciones en Antropología, 11, 41-57.

Chiavazza, H., 2012, Ocupaciones humanas en la planicie árida Noreste de Mendoza: estudios arqueológicos en el Paleocauce Central (PC4): Relaciones de la Sociedad Argentina de Antropología, XXXVII (2), 299-327.

Chiavazza, H., 2015, Estudio de contextos recuperados en los paleocauces del monte árido, NE de Mendoza (Argentina): Anales de Arqueología y Etnología, 70-71, 137-158.

Chiesa, J., Ojeda, G., Font, E., 2015, Geología de las Cuencas de Desaguadero y Bebedero (pleistoceno tardío-holoceno), San Luis, Argentina: Latin American journal of sedimentology and basin analysis, 22(1), 13-28.

Cioccale, M., 1999, Climatic fluctuations in the Central Region of Argentina in the last 1000 years: Quaternary International, 62, 35-47.

Compagnucci, R., Agosta, E., Vargas, W., 2002, Climatic change and quasi-oscillations in central-west Argentina summer precipitation: main features and coherent behaviour with southern African region: Climate Dynamics, 18(5), 421-435.

Cortegoso, V., 2014, Valle de las Taguas, ARQ18: estratigrafia, secuencia temporal y ocupaciones humanas, en Cortegoso, V., Durán, V., Gasco, A. (eds.), Arqueología de
Ambientes de Altura de Mendoza y San Juan (Argentina): Mendoza, EDIUNC, 209-242.

Cruz, L. de la, 1969 [1835], Viaje a su costa del alcalde provincial del muy ilustre Cabildo de la Concepción de Chile: Colección de obras y documentos relativos a la historia antigua y moderna de las provincias de Río de la Plata, Buenos Aires, Editorial Plus Ultra, 230 p.

Dearing, J., 2006, Climate-human-environment interactions: resolving our past: Climate of the Past, European Geosciences Union (EGU), 2, 187-203.

Dincauze, D., 2000, Environmental Archaeology. Principles and practice, Cambridge, Cambridge University Press, 588 p.

Eamus, D., Hatton T., Cook, P., Colvin, C., 2006, Ecohydrology: vegetation function, water and resource management, CSIRO Publishing, Collingwood, Australia, 360 p.

Ebert, J., 1992, Distributional Archaeology, New Mexico, University of New Mexico Press, $296 \mathrm{p}$.

Ericson, J., 1984, Toward the analysis of lithic production systems, en Ericson, J., Purdy, B. (eds.), Prehistoric Quarries and Lithic Production, Cambridge, Cambridge University Press, 1-10.

Font, E., Chiesa, J., 2015, Palaeoenvironmental and climatic reconstruction based on charophytes and sedimentology: Can the mid-Holocene Optimum be recognised in western Argentina?: Aquatic Botany, 120, 31-38

Forman, S., Tripaldi, A., Ciccioli, P., 2014, Eolian sand sheet deposition in the San Luis paleodune field, western Argentina as an indicator of a semi-arid environment through the Holocene: Palaeogeography, Palaeoclimatology, Palaeoecology, 411, 122-135.

Gamble, C., 1993, People on the move: Interpretations of regional variation in Palaeolithic Europe, en Chapman, J., Dolukhanov, P. (eds.), Cultural transformations and interactions in Eastern 
Europe, Avebury, Centre for the Archaeology of Central and Eastern Europe, Ashgate Publishing Company, 37-55.

García, A., 2005, Human occupation of the Central Andes of Argentina $\left(32^{\circ}-34^{\circ} \mathrm{S}\right)$ during the mid-Holocene: Quaternary International, 132, 61-70.

García, A., 2010, Human Occupation during the Mid-Holocene in Western Argentina: Current Anthropology, 51, 415-416.

García, A., 2017, Intensificación económica y complejidad sociopolítica huarpe (centronorte de Mendoza): Intersecciones en Antropología, 18, 157-167.

García-Llorca, J., Cahiza, P., 2007, Aprovechamiento de recursos faunísticos en las lagunas de Guanacache (Mendoza, Argentina). Análisis zooarqueológico de la La Empozada y Altos de Melién II: Chungara, Revista de Antropología Chilena, 39(1), 117-133.

Garreaud, R., Vuille, M., Compagnucci, R., Marengo, J., 2009, Present-day South American climate: Palaeogeography, Palaeoclimatology, Palaeoecology, 281, 180-195.

Gasco, A., Marsh, E., Frigolé, C., Castro, S., Privitera, C., Moyano, R., Yebra, L., 2011, Actividades domésticas durante los siglos III-VIII d.C. en el valle de Potrerillos (San Ignacio-Mendoza). Un acercamiento desde la osteometría y la tecnología cerámica y lítica: Revista del Museo de Antropología, 4, 145-160

Gil, A., 2005, Arqueología de La Payunia (Mendoza, Argentina). El poblamiento humano en los márgenes de la agricultura: La Plata, Argentina, Facultad de Ciencias Naturales y Museo, Universidad Nacional de La Plata, tesis doctoral, $165 \mathrm{p}$.

Gil, A., Zárate, M., Neme, G., 2005, Mid-Holocene paleoenvironments and the archaeological record of Southern Mendoza, Argentina: Quaternary International, 132, 81-94.
Gould, R., 1969, Subsistence behaviour among the Western Desert Aborigines of Australia: Oceania, 39, 253-274.

Gould, R., 1991, Arid-land foraging as seen from Australia: adaptive models and behavioral realities: Oceania, 62, 12-33.

Greslebin, H., 1961, Interrogatorios ranquelinos: Cuadernos del Instituto Nacional de Investigaciones Folklóricas, 2, 51-70.

Grosjean, M., Núñez, L., Cartajena, I., Messer, B., 1997, Mid-Holocene climate and culture change in the Atacama Desert, Northern Chile: Quaternary Research, 48, 239-246.

Gutiérrez, M., Martínez, G., 2015, Arqueología del río Quequén Grande. Cazadoresrecolectores tempranos, cambios ambientales y fauna extinta: Ciencia Hoy, 11, 11-18.

Heider, G., 2015, Los pueblos originarios en el norte de Pampa Seca. Una mirada arqueológica sobre los cazadores-recolectores del sur de Córdoba y San Luis: Córdoba, Argentina, Facultad de Filosofía y Humanidades, Universidad Nacional de Córdoba, tesis doctoral, $441 \mathrm{p}$.

Heider, G., 2016, La gestión de recursos líticos en el Norte de Pampa Seca: Relaciones de la sociedad Argentina de Antropología, XLI(2), 375-396.

Heider, G., 2017, Los recursos vegetales de los Rankülches en la Frontera Sur: Revista TEFROS, 15, 7-25.

Heider, G., Curtoni, R., 2016, Investigaciones arqueológicas en la Provincia de San Luis: a 150 años de sus inicios, historia y perspectivas: Revista del Museo de Antropología, 9(1), 35-48.

Heider, G., López, L., 2016, El consumo de recursos vegetales silvestres en grupos cazadores-recolectores del Norte de Pampa Seca (San Luis y Córdoba, Argentina): Mundo de Antes, 10, 73-99.

Hillel, D., 1998, Environmental soil physics: Fundamentals, applications, and environmental considerations: Academic press, Ámsterdam, 771 p. 
Iriondo, M., 1990, A late Holoceno dry period in the Argentina plains: Quaternary of South America and Antarctic Peninsula, 7, 198-218.

Iriondo, M., 1999, Climatic changes in the South American plains: Records of a continentscale oscillation: Quaternary International, 57-58, 93-112.

Iriondo, M., Kröhling, D., 1995, El Sistema Eólico Pampeano: Comunicaciones del Museo Provincial de Ciencias Naturales Florentino Ameghino, 5, 1-68.

Jobbágy, E., Nosetto, M., Villagra, P., Jackson R., 2011, Water subsidies from mountains to deserts: Their role in sustaining groundwaterfed oases in a sandy landscape: Ecological Applications, 21(3), 678-694.

Jones, T., Brown, G., Raab, M., Mcvickar, J., Spaulding, W., Kennett, D., York, A., Walker, P., 1999, Environmental imperatives reconsidered: demographic crises in Western North America during the Medieval Climatic Anomaly: Gurrent Anthropology, 40(2), 137-170.

Kelly, R., 1995, The Foraging Spectrum: Diversity in Hunter-Gatherer Lifeways, Washington, Smithsonian Institution Press 446 p.

Krömer, R., 1996, Los sedimentos cuaternarios del sudeste de la llanura mendocina. Implicancias paleoclimáticas: Multequina, 5, 49-55.

León, R., Anderson, D., 1983, El límite occidental del pastizal pampeano: Tuexenia, 3, 67-83.

Leroy, S., 2006, From natural hazard to environmental catastrophe: Past and present: Quaternary International, 158, 4-12.

Magliano, P., Murray, F., Baldi, G., Aurand, S., Páez, R., Harder, W., Jobbágy, E., 2015, Rainwater harvesting in Dry Chaco: Regional distribution and local water balance: Journal of Arid Environments, 123, 93-102.

Markgraf, V., 1989, Palaeoclimates in central and south America since 18,000 BP based on pollen and lake-level records: Quaternary Science Reviews, 8, 1-24.
Martínez, G., 2002, Organización y cambio en las estrategias tecnológicas: Un caso arqueológico e implicaciones comportamentales para la evolución de las sociedades cazadorasrecolectoras Pampeanas, en Martínez, G., Lanata, J. (eds.), Perspectivas integradoras entre Arqueología y evolución. Teoría, método y casos de aplicación: Olavarría, INCUAPA, FACSO, UNCPBA, 121-156.

McKee, E., 1979, A study of global sand seas: U.S. Geological Survey, Professional Paper 1052, $429 \mathrm{p}$.

Meglioli, P., Aranibar, J., Villagra, P., Álvarez, J., Jobbágy, E., 2014, Livestock stations as foci of groundwater recharge and nitrate leaching in a sandy desert of the Central Monte, Argentina: Ecohydrology, 7, 600-611.

Mehl, A., Tripaldi, A., Zárate, M.A., 2012, Análisis sedimentológico y cronología del registro cuaternario en el Valle Utracán-Argentino, provincia de La Pampa, Argentina, en XIII Reunión Argentina de Sedimentología, Actas, Asociación Argentina de Sedimentología, Salta, 138-139.

Medina, M., Grill, S., Fernández, A., López, M., 2017, Anthropogenic pollen, foraging, and crops during Sierras of Córdoba Late Prehispanic Period (Argentina): The Holocene, 27(11), 1769-1780.

Meltzer, D., 1991, Altithermal archaeology and paleoecology at Mustang Springs, on the southern High Plains of Texas: American Antiquity, 56(2), 236-267.

Meltzer, D., 1999, Human responses to middle Holocene (altihtermal) climates on the North American Great Plains: Quaternary Research, 52(3), 404-416.

Meltzer, D., Collins, M., 1987, Prehistoric water wells on the southern High Plains: Clues to Altithermal climates: Journal of Field Archaeology, 14, 9-28.

Mollo, N., 2017, Toponimia del Sur de Santa Fe, Córdoba y San Luis: Editorial de la Universidad Nacional de Río Guarto, Río Cuarto, 98 p. 
Morales, M., Barberena, R., Belardi, J., Borrero, L., Cortegoso, V., Durán, V., Guerci, A., Goñi R., Gil, A., Neme, E., Yacobaccio, H., Zárate, M., 2009, Reviewing humanenvironment interactions in arid regions of southern South America during the past 3000 years: Palaeogeography, Palaeoclimatology, Palaeoecology, 281, 283-295.

Nelson, M., 1991, The study of technological organization, en Schiffer, M. (ed.), Archaeological Method and Theory, Arizona, University of Arizona Press, 3, 57-100.

Núñez, L., Grosjean, M., Cartajena, I., 1999, Un ecorefugio oportunístico en la puna de Atacama durante eventos áridos del Holoceno Medio: Estudios Atacameños. Arqueología y Antropología Surandinas, 17, 125-174.

Ots, M., Cahiza, P., Gascón, M., 2015, El río Tunuyán en el Valle de Uco. Mendoza, Argentina: Revista de Historia Americana y Argentina, 50(1), 81-105.

Ots, M., García-Llorca, J., Cahiza, P., 2016, Recursos y estrategias de consumo en el Centro de Mendoza entre los siglos X-XVI AD: Intersecciones en Antropología, 17, 375-387.

Parisii, M., 1991-1992, Algunos datos de las poblaciones prehispánicas del Norte y Centro Oeste de Mendoza y su relación con la dominación Inca del área: Xama, 4-5, 51-69.

Parisii, M., 1995, Aportes documentales y nuevas perspectivas sobre la organización sociopolítica prehispánica del Norte y Centro Oeste de Mendoza: Cuadernos del Instituto de Antropología y Pensamiento Latinoamericano, 16, 121-152.

Pastor, S., 2014, Lomas Negras de Serrezuela. Construcción de un paisaje rupestre entre las Sierras de Córdoba, las Salinas Grandes y Los Llanos de La Rioja: La Plata, Editorial Quire Quire, 43 p.

Pastor, S., Boixados, R., 2016, Arqueología y Etnohistoria: Diálogos renovados en torno a las relaciones entre las sociedades de los llanos riojanos y de las sierras noroccidentales de Córdoba (Períodos Prehispánico Tardío y Colonial Temprano): Diálogo Andino, 49, 311-328.

Prieto, M., Abraham, E., 2000, Caminos y comercio como factores de cambio ambiental en las planicies áridas de Mendoza (Argentina) entre los siglos XVII y XIX: Revista Theomai, 2.

Prieto, M., Chiavazza, H., 2006, Aportes de la Historia Ambiental y la Arqueología para el análisis del patrón de asentamiento Huarpe en el oasis norte de Mendoza: Anales del Instituto de Arqueología y Etnología, 59/60, 163-196.

Rivero, D., Heider, G., 2017, Morfometría geométrica en puntas de proyectil lanceoladas de las sierras centrales (prov. de Córdoba y San Luis). Implicancias para la discusión del poblamiento regional: Revista del Museo de Antropología, Suplemento Especial 1, 75-82.

Rojo, L., Páez, M., Chiesa, J., Strasser, E., Shäbitz, F., 2012, Palinología y condiciones paleoambientales durante los últimos 12.600 Cal. años AP en Salinas del Bebedero (San Luis, Argentina): Ameghiniana, 49(4), 427-442.

Scanlon, B., Levitt, D., Reedy, R., Keese, K., Sully, M., 2005, Ecological controls on water-cycle response to climate variability in deserts: Proceedings of the National Academy of Sciences (USA), 102, 6033-6038.

Schlanger, S., 1992, Recognizing persistent places in anasazi settlement system, en Rossignol, J., Wandsnider, L. (eds.), Space, Time, and Archaeological Landscapes: New York, Plenum Press, 91-111.

Servicio Meteorológico Nacional, 1992, Estadísticas Climatológicas 1991-2000, Buenos Aires.

Soriano, A., 1992, Río de la Plata Grasslands, en Copeland, R.T. (ed.), Ecosystems of the World. Natural Grasslands, Introduction and Western Hemisphere: New York, Elsevier, 
367-407.

Sperry, J., Adler, F., Campbell, G., Comstock, J., 1998, Limitation of plant water use by rhizosphere and xylem conductance: results from a model: Plant, Cell \& Environment, 21(4), 347-359.

Tripaldi, A., 2002, Sedimentología y evolución del campo de dunas de Médanos Grandes (provincia de San Juan, Argentina): Revista de la Asociación Argentina de Sedimentología, 9(1), 65-82.

Tripaldi, A., 2010, Campos de dunas de la planicie sanrafaelina: patrones de dunas e inferencias paleoclimáticas para el Pleistoceno tardíoHoloceno, en Zárate, M., Gil, A., Neme, G. (eds.), Paleoambientes y ocupaciones humanas del centro-oeste de Argentina durante la transición Pleistoceno-Holoceno y Holoceno: Buenos Aires, Sociedad Argentina de Antropología, 65-93.

Tripaldi, A., Forman, S., 2007, Geomorphology and chronology of Late Quaternary dune fields of western Argentina: Palaeogeography, Palaeoclimatology, Palaeoecology, 251, 300-320.

Tripaldi, A., Limarino, C., 2004, Hierarchic classification and mapping of modern eolian fields of northwestern Argentina, en 32 $2^{\text {nd }}$ International Geological Congress, Florence, Italy, Abstract, 1, 256-261.

Veth, P., 1989, Island in the interior: a model for the colonization of Australia's arid zone: Archaeology in Oceania, 24 (3), 81-91.

Veth, P., 1995, Aridity and settlement in northwest Australia: Antiquity, 69, 733-746.

Veth, P., 2005, Conclusion Major Themes and Future Research Directions, en Veth, P., Smith, M., Hiscock, P. (eds.), Desert Peoples: Archaeological Perspectives: Victoria, Australia, Blackwell Publishing, 293-300.

Vignati, M., 1940, Culturas prehistóricas y protohistóricas de la provincia de San Luis. Antecedentes bibliográficos: Los Precursores: Notas del Museo de La Plata: Antropología, 20(5), 149-176.
Vilanova, I., Karsten, S., Geilenkirchen, M., Schäbitz, F., Schulz, E., 2015, Last millennial environmental reconstruction based on a multi-proxy record from Laguna Nassau, Western Pampas, Argentina: Neues Jahrbuch für Geologie und Paläontologie Abhandlungen, Schweizerbart'sche Verlagsbuchhandlung, 277(2), 209-224.

Vilanova, I., Tripaldi, A., Piovano, E., Forman, S., Chiesa, J., Jobbágy, E., Rojo, L., Heider, G., Schittek, K., 2017, Vegetation and environmental changes related to hydroclimate regimes in Wester Pampas, Argentina, over the last $1.5 \mathrm{kyr}$ : 5th Open Science Meeting. Global Challenges for our Common Future: a paleoscience perspective (PAGES OSM 2017), 406 p.

Villagra, P., Roig, F., 1999, Vegetación de las márgenes del Río Mendoza en su zona de divagación (Mendoza, Argentina): Kurtziana, 27, 309-317.

Wang, X., Berndtsson, R., Li, X., Kang, E., 2004, Water balance change for a re-vegetated xerophyte shrub area: Hydrological Sciences Journal, 49, 283-296.

Webb, K., 1993, The lithification of a sandy environment: Archaeology in Oceania, 28, 105-111.

Zárate, M., 2003, The loess record of southern South America: Quaternary Science Reviews, 22, 1987-2006.

Zárate, M., 2006, Desde los andes mendocinos a la costa Atlántica bonaerense: paleoambientes y paleoclimas de los últimos 14000 años, en Actas III Congreso Argentino de Cuaternario y Geomorfología: Córdoba, Argentina, Tomo I, 277-287.

Zárate, M., Neme, G., Gil, A., 2005, Mid Holocene paleoenvironments and human occupation in southern South America: Quaternary International, 132, 1-3.

Zárate, M., Tripaldi, A., 2012, The aeolian system of central Argentina: Aeolian Research, 3, 401-417. 